\title{
IIHS Twenty Priorities to consider during a Lockdown and Health Emergency
}

\section{Twenty Essential Things to Do}

1. Strengthen District \& State Situation/'War' Rooms: staff them with key personnel from line departments to keep essential services functional and prepare for restoration. Establish GIS and analytical capacity to track hot spots and bottlenecks. Establish emergency communication capacity for social and broadcast media. Enable information flows from support hotlines and call centres to respond to citizen, stakeholder and frontline staff queries and identify bottlenecks.

2. Augment health systems, emergency services and pharma \& medical supply chains: as per relevant advisories and good practices. Needs separate guidance and specialized actions not outlined here.

3. Secure statewide ICT infrastructure and ensure functioning services: phone, mobile phone, internet, TV, print and electronic media to enable connectivity for all citizens, and an open and transparent interface with state and local administration. Establish helplines to respond to citizens in distress, highly vulnerable and special groups (e.g. migrants) with private sector support.

4. Strengthen Banking, Post Office, ATM \& Treasury services: required for the delivery of direct cash transfers, enhanced pensions etc. and keeping essential services and government functioning moving. If cash supply is reported to be low, consider replenishing local cash supplies, which is the lifeline of the informal economy.

5. Strengthen and Augment PDS \& public services: required for the delivery of in-kind support (e.g. food, civil supplies, kerosene and LPG) including tracking stocks, enabling daily movement, and protecting and supporting the informal sector workers, who keep these systems running. Special care to maintain supplies to Aanganwadi and midday meal programmes, hospitals and critical care facilities and to elderly, vulnerable and remote populations.

6. Emergency Passenger evacuation/transport: by road and possibly by rail, with adequate authorization and provision of shelter, food, health screening, medication or quarantining, to address the needs of lakhs of migrant workers and those requiring emergency medical attention, bereavement etc.

7. Maintain stable Power supply: focusing on distribution infrastructure to ensure uninterrupted residential and agricultural power during the lockdown, and rapid post- lockdown restoration.

8. Maintain stable Fuel supply: and appropriate stocks (of diesel, petrol, LPG and CNG) to maintain goods transportation, emergency services vehicles; backup or captive power supply to critical infrastructure (e.g. mobile towers, telecom systems and data centers, hospitals); critical manufacturing facilities, warehouses and cold chains, agriculture and allied activity, and prepare for the surge in public and private passenger demand post-lockdown.

9. Maintain and expand goods transport: by rail, road and air, to maintain intrastate and interstate movement of food and essential supplies, continuous process and strategic production units, and rapid restoration post-lockdown. Local relaxations may be necessary to support rabi operations.

10. Maintain warehouses and cold chain services: to support the PDS and essential services system, by tracking and ensuring adequate stocks of supplies and functioning, protection of public, private and informal sector workers, security of facilities and adequate power, water supply sand waste management services.

11. Maintain supply chains for essential services: by addressing bottlenecks in underlying lifeline services and informal-informal sector arrangements across distribution and retail chains. Opening a dialogue with key stakeholders and enabling a staged relaxation of lockdown conditions.

12. Maintain stable water supply services: to limit the risk of water-related diseases, with large populations locked down in dense conditions in urban and rural areas. Regular pipeline-based or tanker supply to water-scarce areas. Stable power where supply depends on pumping groundwater.

13. Maintain stable sanitation and solid waste services: to maintain sanitary conditions, especially with large numbers of people in lockdown. Enhanced protection of frontline sanitation and solid waste workers., exposed to COVID-19.

14. Support farm and non-farm Activity: to support the expected bumper rabi harvest starting in April 2020, including relaxation in the movement of farm workers, with adequate screening and protection, farm equipment and agricultural supplies.

15. Maintain irrigation services: to stabilise the supply of vegetables and fruit, protect the sowing of summer crops and rapid service restoration post-lockdown.

Aromar Revi (arevi@iihs.co.in) IHSS Twenty Priorities to consider during a Lockdown and Health Emergency 
16. Ramp-up the production of essential materials: e.g. drugs, medical supplies, food, cooked food, household supplies, refining of fuel in-state, or alternate inter-state arrangements.

17. Protect Workers and their livelihoods: especially migrants and those in the informal sector. Stockpiling and distribution of Personal Protective Equipment (PPE) to all frontline health and sanitation workers. Appropriate protection and training measures to other near-frontline workers maintaining law and order, administrative, lifeline infrastructure and essential supply functions.

18. Address the needs of migrant workers and migrant families

19. Address the needs of the vulnerable groups: e.g. the homeless, elderly, prisoners, mentally ill and persons with disability.

20. Address the emerging hunger and malnutrition crisis: and its consequent impact on mortality and morbidity, especially among poor, vulnerable, undernourished children and women

\section{A Dozen Key Process Questions to be Addressed}

1. Where is the expected need/demand for commodities/services going to come from? At what frequency will it require replenishment? Who is the nodal institution/person responsible?

2. Where are key stocks of supplies located? How can they be replenished? Who controls them? How can they be requisitioned? How can large stocks be secured?

3. Where are the key transportation and logistics systems/vehicles located? Do they have adequate fuel and personnel to handle movement, transshipment, delivery? Who controls them? How can they be requisitioned and authorized? How can they be serviced and maintained?

4. Who are the critical personnel required to operate and manage lifeline infrastructure \& services? How can they and their families be kept secure? How can they be securely moved to their places of work?

5. Where are the financial resources required to pay for supplies, personnel $\&$ transport? Who will release them? At what frequency? Under whose authority?

6. Are there mechanisms in place to regulate and enforce prices of essential commodities and widely available information on what these prices are set at?

7. Is the production of food, civil supplies and essential commodities continuing? If not, how can these units be restarted and augmented, or cross-border logistics arrangements made?

8. What are the regular/emergency regulations or administrative orders required to execute these action? Who is responsible for issuing them? Who is responsible for oversight?

9. Is information on each of these questions flowing to each district control room and being physically or digitally mapped each day? Is aggregated information flowing to the State Situation room? Are bottleneck locations, institutions, and networks being identified each day? Are these being cleared? Who is responsible for oversight?

10. Is there a contingency plan to address scarcity of resource flows? Does this prioritise the poor and vulnerable and remote locations? Who is responsible for oversight?

11. Is there an emergency communication plan in place and channels of emergency communication, in place from: citizens, stakeholders, local functionaries to district and state situation rooms?

12. Is there a contingency plan to maintain law and order and maintain essential services and supplies with Army and paramilitary force assistance, if the civil administration needs to call upon them? 